\title{
O conceito de trabalho na perspectiva de crianças e adolescentes: uma análise a partir da teoria piagetiana
}

\author{
Maria de Lourdes Mattos Barreto ${ }^{1}$ \\ Gisele Maria Costa Souza ${ }^{2}$ \\ Márcia Onísia da Silva ${ }^{3}$
}

\begin{abstract}
RESUMO
A evolução do conhecimento social, utilizando o método clínico piagetiano, tem sido estudada com o objetivo de verificar como as crianças e adolescentes representam o mundo à sua volta. Partindo da indagação: "quais as representações de crianças e adolescentes sobre trabalho?" objetivou-se, nesse estudo, buscar a gênese do conceito de trabalho, analisando essas representações ao longo do desenvolvimento de crianças e adolescentes. Por meio das entrevistas clínicas realizadas com 60 sujeitos, obteve-se 4 níveis de conhecimento, identificando desde as ideias de que o trabalho é comprado, indo para uma noção de que é necessário à sobrevivência humana até as relações sociais de trabalho e de formação necessária para exercício profissional. Demonstrou-se que este tipo de conhecimento é construído e coerente com a estrutura cognitiva, influenciados pelo meio social, mas não determinadas por ele.
\end{abstract}

PALAVRAS-CHAVE: Crianças e Adolescentes. Trabalho-conceito. Representações. Método Clínico Piagetiano.

The concept of work in the perspective of children and adolescents: an analysis based on the Piagetian theory

\footnotetext{
${ }^{1}$ Doutora em Educação. Universidade Federal de Viçosa, Viçosa, MG, Brasil. E-mail: mmattos@ufv.br.

${ }^{2}$ Doutora em Motricidade Infantil. Universidade Federal Rural do Rio de Janeiro, Seropédica, RJ, Brasil. E-mail: gisele.souza@hotmail.com.

${ }_{3}^{3}$ Mestre em Economia Doméstica. Universidade Federal de Viçosa, Viçosa, MG, Brasil. E-mail: monisia@ufv.br.
} 


\begin{abstract}
The evolution of social knowledge, using the Piagetian clinical method, has been studied in order to verify how children and adolescents represent the world around them. Starting from the question: "what representations of children and adolescents about work?", The purpose of this study was to search for the genesis of the concept of work, analyzing these representations throughout the development of children and adolescents. Through clinical interviews with 60 subjects, 4 levels of knowledge were obtained, identifying from the ideas that the work is bought, going to a notion that it is necessary to human survival to social relations of work and that requires appropriate training for professional practice. It has been shown that this type of knowledge is constructed and consistent with the cognitive structure, influenced by the social environment, but not determined by it.
\end{abstract}

KEYWORDS: Children And Adolescents. Work-Concept. Representations. Clinic Piaget Method.

\title{
Introdução
}

O conhecimento social é uma das formas de conhecimento consideradas por Piaget e deriva das trocas com os outros indivíduos por meio das interações e transmissões sociais que o sujeito estabelece no decorrer de sua vida. Esse tipo de conhecimento evolui de forma mais simples na infância para formas mais elaboradas, quando o indivíduo atinge a adolescência. Nossa proposta foi verificar como se dá a construção do conhecimento sobre a categoria trabalho por crianças e adolescentes, considerando que são seres ativos na construção de seu próprio conhecimento e que este é construído na interação com o meio físico e social, não copiando os dados da realidade, mas os transformando ativamente.

Ao eleger as crianças e adolescentes como fonte de estudo para a compreensão da sociedade e da família, é necessário situar qual a concepção de criança e de adolescente norteia a investigação, pois a visão de criança e 
adolescente varia de acordo com a sociedade e em diferentes períodos históricos. Historicamente, essa visão passa por mudanças marcantes no decorrer do tempo, e pesquisa como a de Ariès (1986) indica como essa visão foi sendo construída em diferentes momentos na história da humanidade. Ariès realizou estudos sobre a história da infância por meio de muitas fontes, utilizando a iconografia religiosa e leiga, os registros de batismo e os diários de família, entre outros.

Educadores como Rousseau (1712-1778), Pestalozzi (1746-1827) e Froebel (1782-1852) introduziram novas concepções sobre a criança, afirmando que ela tem natureza peculiar, boa, sensível e merece atenção diferenciada do adulto. Atualmente, a criança é considerada um ser ativo na construção do próprio conhecimento e, conforme Piaget (1967), o desenvolvimento se dá por estágios que têm uma sequência e uma ordem lógica.

Salles (2005) apontou que, atualmente, a criança e o adolescente são concebidos como sujeitos com modos específicos de se comportar, agir e sentir. Essa visão indica que devem ser compreendidos a partir da relação estabelecida entre eles e os adultos. Uma influência mútua se institui de acordo com as condições objetivas da cultura na qual se insere, a partir de condições históricas, políticas e culturais diferentes.

É importante ouvir a criança e, nesse sentido, Cruz (2008) reiterou que a fala da criança e do adolescente pode subsidiar ações a seu favor e contribuir para mudanças que as beneficiem, em razão dos elementos que seu ponto de vista traz, fortalecendo pessoas e entidades preocupadas com seus interesses e que desenvolvem ações voltadas para a construção de melhores condições da vivência da infância. Por isso, é necessário que a criança e o adolescente saibam o que vai ser feito e participem, de forma consciente e voluntária, do estudo. Criança não trabalha! Porque pesquisar suas representações sobre uma temática tão distante de sua realidade?

A criança enquanto sujeito histórico-cultural se constitui em uma sociedade e na sua cultura. Procuramos compreender a constituição desse 
sujeito, via de regra, estudando suas manifestações visíveis: cotidiano, saúde física, crescimento/desenvolvimento, nutrição, habitação, oportunidades de lazer, acesso a bens e serviços específicos, dentre outros. Essas análises, embasadas em teorias psicológicas, educacionais, sociológicas, biológicas e econômicas visam oferecer sempre um panorama de como as crianças estão e como podem ficar a partir de políticas públicas e da instituição de direitos, atribuindo às famílias e ao Estado, a responsabilidade por seu bem estar.

No entanto, deve-se acrescentar a elas, o "falar" da criança. O que ELA nos tem a dizer? Como se sente diante do mundo que a cerca? O que ela gostaria que fosse criado/melhorado nesse seu mundo? Por essas questões, é que o trabalho enquanto categoria de análise deve ser incluído nas pesquisas com crianças. Diante do papel que ocupa na vida das pessoas, a importância social que assume, a criança (que não trabalha) está diretamente ligada nesse universo, por meio das interações que estabelece com seus pares, especialmente, com seu grupo familiar.

Esse trabalho é um recorte da dissertação de mestrado, intitulada "Representações de Crianças e Adolescentes sobre trabalho numa perspectiva Piagetiana" e parte das seguintes questão: quais as representações de crianças e adolescentes, na faixa etária de 4 a 14 anos, sobre trabalho? Diante dessa indagação, realizou-se uma pequisa qualitativa, do tipo ex-post facto, constituída pelo objetivo de analisar por meio de um estudo evolutivo as representações de crianças e adolescentes sobre a categoria trabalho, buscando a conceituação presente nessas representações.

\section{A ideia de trabalho em diferentes momentos da história humana}

O termo trabalho pode assumir vários significados e receber conotações e sentidos diversos de acordo com a cultura. Carmo (2005) afirmou que sua origem no latim tripalium denota instrumento formado por três estacas, cuja função era a de manter presos bois e cavalos difíceis de ferrar. Sua 
tradução no latim vulgar significa "pena ou servidão do homem à natureza". $\mathrm{Na}$ língua alemã arbeit e no latim laborar, o sentido é de algo penoso. A definição apresentada pelo autor é de que o trabalho é toda atividade humana realizada pelo homem civilizado que transforma a natureza com sua inteligência (CARMO, 2005).

Migeotte (2005), revisitando a Antiguidade Grega, afirmou que as primeiras reflexões sobre o trabalho surgiram nas obras homéricas e, posteriormente, em Hesíodo, por volta do ano 700 a.C., além de outras obras poéticas do período arcaico. O ponto culminante dessas reflexões ocorre no período clássico, nos século V e IV, nos textos de Xenofontes e Platão, inspirados nas obras de Sócrates, especialmente em seu livro Política. A maneira de ver o trabalho pelos gregos estava ligada à concepção que tinham da economia como um vasto conjunto de produção, de trocas e de consumo.

Predominou, conforme Carmo (2005), na Idade Média o regime de servidão, entendido como um meio-termo entre o trabalho-escravo e o trabalho livre. Vigorava também, nesse período, uma visão contrastante entre o catolicismo - para o qual o trabalho era considerado penitência para o pecado e ensejo para obter redenção divina, e o protestantismo - para o qual o trabalho era considerado meio de obter riqueza, mas também de servir a Deus, à medida que mantinha à distância o ócio e a luxúria.

Ramalho (2004) considerou que as transformações no mundo do trabalho afetam as sociedades, principalmente as industriais, de forma intensa. A produtividade tão valorizada atualmente é enfatizada na busca pela competitividade e qualidade, as quais são marcadas pelas inovações tecnológicas e novas formas de gestão das forças de trabalho. Para Morin et al. (2007), a partir de meados dos anos de 1950 vários pesquisadores buscaram compreender o significado do trabalho para as pessoas, utilizando diferentes metodologias. As pesquisas apontaram para uma conceituação de trabalho em que este é considerado essencial na vida das pessoas, uma vez que garante a sobrevivência. 
Estudo de Morin (2002) apontou para as seguintes características do trabalho, as quais possibilitam que tenha sentido: o trabalho deve ser feito de maneira eficiente, levando a um resultado útil; precisa ser satisfatório, possibilitando a obtenção de prazer e satisfação na realização das tarefas, permitindo ao trabalhador a resolução de problemas, uso do talento e potencial, com autonomia; precisa ter aceitação moral, denotando responsabilidade social; constituir-se como fonte de experiências de relações humanas aceitáveis; deve garantir segurança, por meio do vínculo empregatício; e a condição de receber um salário que permita a sobrevivência.

Dessa forma, nas considerações de Carmo (2005), o trabalho ocupa lugares e momentos diversos na vida humana, o que já demonstra a importância dele para a nossa sociedade. Para esse autor, pode-se considerar trabalho a atividade das plantas, dos animais, das máquinas, dos atletas, do pintor, do aluno, da bailarina etc., como se tudo na vida se resumisse ao trabalho, indiferente das diversas facetas que ele assume em nossa sociedade. Com o surgimento do capitalismo, grandes mudanças se colocaram na frente do pensamento medieval, passando a imperar o produtivismo.

Pesquisar essa categoria enquanto campo do conhecimento social é de importância vital para compreender a sociedade e os desdobramentos que mudanças no universo do trabalho acarretam na vida das pessoas e como afetam a infância. Faz-se necessário esse estudo delimitando a teoria que orienta a análise e, em razão disso, optou-se pela Teoria de Piaget para que tal busca fosse a efeito.

\section{O conhecimento social na teoria de Piaget}

As interações sociais são de fundamental importância para o desenvolvimento do indivíduo, e Chakur (2002) mencionou que a inteligência em sua forma lógica depende do desenvolvimento orgânico do 
indivíduo e da estimulação ambiental. No campo do conhecimento social, é de extrema importância o meio em que a criança se insere, pois as interações e transmissões sociais podem estar carregadas de preconceitos e são formas diretas de transmissão de valores e regras. Para Piaget (1973), a sociedade é formada por um sistema de atividades em que as ações do sujeito e o meio se modificam mutuamente. O conhecimento social origina-se na cultura e difere de uma cultura para outra, sendo construído pela criança enquanto interage com outras crianças e com adultos e não pode ser extraído das ações sobre os objetos, como acontece com o conhecimento físico e não depende só do sujeito.

Conforme La Taille (1992), a maneira de ser social de adolescentes e de crianças é diferente, pois as crianças não são capazes ainda de participar de relações sociais que expressem equilíbrio de trocas intelectuais. É necessário, então, que o sujeito possua estrutura lógica para que ocorra a assimilação do conhecimento, seja ele conhecimento físico, lógicomatemático ou social.

Wadsworth (1987) afirmou que, para Piaget, as transmissões sociais são fatores do desenvolvimento, não respondendo por si só pelo desenvolvimento da criança como querem crer algumas correntes. A experiência social é um processo ativo do mesmo modo que a experiência física, sendo necessário examiná-la, pois é instrumental no processo de desenvolvimento. As crianças aprendem muitas coisas através de outras pessoas, de suas ações com estas e das interações estabelecidas.

Piaget (1973) distinguiu diferenciações nas relações sociais da criança desde seu nascimento até a formação da personalidade, a última fase do desenvolvimento social. A afetividade da criança sensoriomotora deriva de um estado de não diferenciação do eu e todos os elementos físicos e humanos que o cercam. Com o aparecimento da representação, no período préoperatório, o objeto afetivo poderá ser evocado mesmo em sua ausência física, e esse fato acarreta a formação de novos afetos, como a simpatia ou antipatia duradouras que são dirigidas ao outro. A partir do estágio 
operatório, as trocas intelectuais começam a ir em direção ao equilíbrio, alcançando, nesse nível, o que Piaget denominou personalidade.

No estágio operatório concreto, a criança já é mais sociável e menos egocêntrica, utilizando de forma mais eficaz, a linguagem, podendo descentrar e considerar diferentes pontos de vista, mas ainda aplicando soluções apenas a problemas concretos. No estágio operatório formal, o sujeito já é capaz de lidar com classes de problemas diferentes, raciocinando sobre os hipotéticos e abstratos de forma eficiente. Significa que o indivíduo se submete voluntariamente às normas de reciprocidade e de universalidade. A personalidade constitui o produto mais refinado da socialização e é a capacidade de inserir seu ponto de vista entre os outros. (PIAGET, 1973).

Trabalho se compra, trabalho se faz, trabalho é para ganhar dinheiro - a evolução das representações das crianças e dos adolescentes: apresentação da metodologia e dos resultados

Para atender nossos objetivos, fundamentamos a pesquisa no Método Clínico Piagetiano, realizando as entrevistas clínicas com as crianças e adolescentes, levantando e sistematizando as categorias presentes em suas respostas. A pesquisa possui abordagem descritivo-comparativa, pois partimos da teoria piagetiana, que pressupõe que o conhecimento é construído e evolui de forma mais simples para uma mais elaborada e é uma construção ativa do sujeito, através de um processo contínuo de assimilação e equilibração (PIAGET, 1967; 1964; 1968).

A população foi composta por crianças e adolescentes matriculados em uma escola da rede particular de Viçosa, MG. A população atendida nessa escola caracterizava-se por crianças de classe média e classe média alta, oriundas de famílias residentes na cidade de Viçosa. A amostra do estudo foi constituída de 10 crianças de cada grupo etário, compreendendo a média de idade de $4 ; 6 ; 7 ; 10 ; 11$; e 14 anos, totalizando 60 sujeitos. A definição de 
criança e de adolescente adotada nesta proposta baseou-se no Estatuto da Criança e do Adolescente - ECA (1990), que considera criança a pessoa até 12 anos de idade incompletos, e adolescente aquela entre 12 e 18 anos de idade (ECA, 1990).

Sendo um estudo transversal, que se caracteriza pela análise de diferentes grupos de sujeitos de idades distintas, a definição das faixas etárias se deu em função da necessidade de cobrir, teoricamente, três estágios de desenvolvimento - pré-operatório, operatório concreto e operatório formal, o que permitiu obter dados evolutivos, examinando-se um número apropriado de sujeitos. Para a seleção da amostra, utilizamos a técnica da amostragem intencional, que segundo Marconi e Lakatos (1999), é um tipo de amostragem não probabilística, na qual se escolhem intencionalmente os sujeitos que farão parte do estudo. Utilizou-se como referência para análise das respostas, o quadro proposto por Delval (2002).

Iniciamos a descrição dos resultados mostrando como, em cada nível de desenvolvimento, crianças e adolescentes representaram a categoria "trabalho". O conceito de trabalho parte da identificação do que é trabalho para crianças e adolescentes, buscando as noções subjacentes às ideias principais acerca do tema. Na Tabela 1 são apresentados os percentuais de crianças e adolescentes encontrados em cada nível, sendo:

\section{A - Conceito: $O$ que é trabalho - constituição e evolução}

B - As estratégias de entrada no mercado de trabalho (Como se consegue um trabalho)

Tabela 1: Percentuais de crianças e adolescentes em cada nível, segundo a categoria conceito de trabalho

\begin{tabular}{|c|c|c|c|c|c|c|c|c|c|c|c|c|c|c|c|c|c|c|c|c|}
\hline \multicolumn{21}{|c|}{ CONCEITO DE TRABALHO } \\
\hline $\begin{array}{l}\text { Faixa } \\
\text { etária }\end{array}$ & \multicolumn{4}{|c|}{$O$ que é trabalho } & \multicolumn{4}{|c|}{$\begin{array}{c}\text { Como se consegue } \\
\text { Trabalho }\end{array}$} & \multicolumn{4}{|c|}{$\begin{array}{c}\text { Extensão } \\
\begin{array}{c}\text { (quem são as pessoas que } \\
\text { trabalham) }\end{array}\end{array}$} & \multicolumn{4}{|c|}{$\begin{array}{c}\text { Mudança } \\
\text { (como se entra ou sai do } \\
\text { trabalho) }\end{array}$} & \multicolumn{4}{|c|}{ Média (\%) } \\
\hline & PI & I & II & III & PI & $\mathbf{I}$ & II & $\begin{array}{c}\text { II } \\
\text { I }\end{array}$ & PI & I & II & III & PI & $\mathbf{I}$ & II & III & PI & $\mathbf{I}$ & II & III \\
\hline 4 & 100 & - & - & - & 100 & - & - & - & 100 & - & - & - & 100 & - & - & - & 100 & - & - & - \\
\hline 6 & 60 & 40 & - & - & 60 & 40 & - & - & 80 & 20 & - & - & 80 & 20 & - & - & 70 & 30 & - & - \\
\hline
\end{tabular}




\begin{tabular}{|c|c|c|c|c|c|c|c|c|c|c|c|c|c|c|c|c|c|c|c|c|}
\hline 7 & 10 & 90 & - & - & 10 & 90 & - & - & 40 & 60 & - & - & 20 & 80 & - & - & 20 & 80 & - & - \\
\hline 10 & - & 20 & 80 & - & - & 20 & 80 & - & - & 10 & 90 & - & - & 10 & 90 & - & - & 15 & 85 & - \\
\hline 11 & - & - & 70 & 30 & - & - & 70 & 30 & - & - & 80 & 20 & - & 50 & 50 & - & - & $\begin{array}{c}12 \\
5\end{array}$ & 67,5 & 20 \\
\hline 14 & - & - & 40 & 60 & - & - & 40 & 60 & - & - & 70 & 30 & - & - & 70 & 30 & - & - & 55 & 45 \\
\hline
\end{tabular}

Fonte: Dados da pesquisa.

Legenda: PI - Nível Pré-I; I - Nível I; II - Nível II; III - Nível III

\section{A - Constituição e evolução do conceito de trabalho}

Como pode ser observado na tabela 1, para a subcategoria "o que é trabalho", encontramos no nível Pré-I 100\% das crianças de 4 anos, $60 \%$ das crianças de 6 anos e 10\% das crianças de 7 anos de idade. O nível Pré-I caracteriza-se pela ausência de conceitos elaborados e de uma visão prática e ligada ao real. O mundo concreto está presente de forma decisiva na visão de crianças na faixa etária de quatro a sete anos de idade. Para estas crianças, o trabalho é algo que os adultos e, especialmente, seus pais fazem com a finalidade de ganhar dinheiro. Quando solicitadas a dizer o que é trabalho as crianças deste nível apresentam ideias pouco elaboradas, muito voltadas às ações que as pessoas executam.

No nível Pré-I encontramos $30 \%$ de respostas fabuladas e nãoimportistas. Há ausência de sistemas interpretativos e, devido a isto, a criança não entende bem o que é trabalho, conceituando-o em função das atividades que seus pais fazem. Os conceitos são pré-conceitos, ligados ao real e ao concreto. Crianças no nível Pré-I sabem que o trabalho é algo que as pessoas fazem para ganhar dinheiro, fazendo uma relação direta entre estas duas variáveis. O finalismo está presente nas respostas das crianças analisadas e, em consequência disso, o trabalho não é conceituado em relação ao "o que é", mas "para que serve". Essas características podem ser constatadas nas falas das crianças dos extratos a seguir.

- O que você acha que é trabalhar? É dá aula pros alunos... fazer curso... - Isso é trabalhar? (balança a cabeça em sinal positivo). Porque você acha que as pessoas trabalham? Pra ganhar dinheiro.

- Por que você acha que as pessoas precisam de dinheiro? Pra 
comprar coisas... mas pelo menos os de rua, não... né? Os de rua é pobre. (Criança 1, 4;4 anos, nível Pré-I).

- Ah! Vender cerveja... vender café... - Quem vende cerveja, vende café está trabalhando? - Tá! . - Porque você acha que as pessoas trabalham? Elas ganham dinheiro. - Porque você acha que as pessoas precisam de dinheiro? Pra...comprar coisas...vender cerveja...pra ganhar dinheiro. (Criança 6, de 6;5 anos, nível Pré-I).

Fazer coisa pra ganhá dinheiro. - Porque você acha que as pessoas trabalham? Pra ganhar dinheiro. - Por que você acha que as pessoas precisam de dinheiro? Pra pagar conta... comprá coisas... (Criança 10, de 7,7 anos, nível Pré-I).

Percebe-se, nesta faixa etária, uma dificuldade em conceituar o trabalho, mas as crianças já o relacionam com a necessidade de ganhar dinheiro. Já aparece neste início de construção do conhecimento a ideia do trabalho como uma atividade dos adultos e uma percepção da divisão de classes presentes na sociedade, onde alguns têm acesso ao trabalho, outros não.

Este resultado mostra a mobilidade presente em cada nível. Conforme Delval (2002), para as crianças menores o trabalho é algo misterioso do qual tinham ouvido falar, que seus pais faziam, mas não sabiam exatamente o que é e quais as razões para receberem, em troca, dinheiro. Esses dados foram encontrados também em nossa pesquisa confirmando essa característica, embora em nossa pesquisa as crianças demonstraram relacionar a finalidade do trabalho com a obtenção do dinheiro e este, por sua vez, serve para compra de bens de consumo.

No nível I as crianças relacionam o trabalho ao ganho de dinheiro e esta agora se mostra como uma finalidade específica, aparecendo já na definição que apresentam ao termo. Como pode ser visto na tabela 1 , encontramos $40 \%$ de crianças de seis anos, $90 \%$ das crianças de sete anos e 
20\% das crianças de dez anos no nível I, não sendo encontradas crianças de outras faixas etárias neste nível. As frases das crianças do nível I são mais completas do que as das crianças do nível Pré-I. O vocabulário é mais definido e há mais coerência em suas respostas. Entretanto, encontramos respostas finalistas, assim como as apresentadas pelas crianças do nível anterior. As crianças de sete anos apresentam uma forte tendência de exemplificar suas respostas, como pode ser visto nos extratos a seguir.

- O que você acha que é trabalhar? - É...tipo....a gente...sair de casa pra ganhar dinheiro. - Porque você acha que as pessoas trabalham? Pra ganhar dinheiro. - Por que você acha que as pessoas precisam de dinheiro? Porque... muitas coisas importantes... tipo... tem muitas coisas que a gente precisa de comprar. (Criança 4, de 6;9 anos, Nível I).

- Trabalhar? É tipo assim...minha mãe... ela trabalha, ela dá aula de Inglês na universidade...aqui à noite...de manhã e de tarde, isso é...ela trabalha. Meu pai...ele é dono de uma farmácia e ganhava muito, aí ele vendeu uma farmácia e só tá com a manipulação...ele trabalhava ne outro lugar e na manipulação...ele também trabalha. Ele vende é... as pessoas vão lá, pedem pra fazer o remédio que elas precisam, meu pai manda fazer...e pede pro moço entregar na casa delas ou pede pra elas buscar lá. Tem vários tipos de trabalho- Porque você acha que as pessoas trabalham? Pra ganhar dinheiro, se tiver filho pra sustentar, se tiver que comprar comida, cobertor...e pra pagar a casa...aluguel...água...luz...tipo...os bichos, eles matam outros bichos pra comer...tipo o leão...- Você acha que isso é o trabalho deles? Não. Pra sustentar eles...tipo assim...se eles não caçasse nenhum, ele ia morrer de fome. (Criança 2, de 7;5 anos, nível I).

Por volta dos seis/sete anos as crianças iniciam uma transição para o estágio operatório concreto caracterizado pelo pensamento concreto, baseado nas percepções da realidade, mas com modificações importantes no 
desenvolvimento mental, em que surgem novas formas de organização, atingindo um equilíbrio mais estável. A queda acentuada do egocentrismo permite a coordenação de pontos de vista diferentes. Entretanto, há indícios de que a construção do conhecimento social é relativamente mais vagarosa do que as transformações cognitivas alcançadas até agora e, conforme Delval (2002), as explicações para este fato não estão ainda muito claras. Pode-se considerar que o mundo social é mais complexo do que o mundo físico, pois os problemas para este último são facilmente materializáveis por meio de situações com materiais concretos como varetas, pêndulos, sombras e o mesmo não ocorre com os fenômenos sociais.

Aproximadamente aos sete anos as crianças iniciam uma transição para o pensamento operatório concreto, o que significa o desenvolvimento da habilidade de aplicar o pensamento lógico a problemas concretos. O quadro de referências conceitual parece mais estável e regular, aplicando-se sistematicamente ao mundo de objetos que rodeia a criança. Com o declínio do egocentrismo e o pensamento tornando-se lógico, a realidade começa a ser estruturada pela razão e não mais pela assimilação egocêntrica. Entretanto, embora o pensamento seja lógico, ele é restrito ao mundo concreto.

Um número significativo das crianças de sete anos (70\%) afirmou que há necessidade de se ter dinheiro para "comprar" o trabalho. É nesta faixa etária que este tipo de resposta é mais recorrente e é uma das características mais marcantes das respostas. Delval (2002) afirma que este tipo de resposta se deve ao fato de a criança, em busca de explicações, generalizar a partir de situações que não conferem com as que têm diante de si. Há falta de compreensão das limitações externas, como a escassez de trabalho ou de bens.

Já no nível II, uma característica que diferencia as crianças das de nível anterior é o surgimento da ideia de um processo de qualificação por meio de estudos e de cursos para obtenção de trabalho. O trabalho se converte na principal forma de mudança, mas os trabalhos se diferenciam de 
acordo com sua qualidade. Os extratos a seguir exemplificam as falas das crianças.

- O que você acha que é trabalhar? Trabalhar é primeiro você faz um curso pra poder ter um emprego, e depois você consegue um trabalho em algum lugar e trabalha pra ganhar algum lucro.Porque você acha que as pessoas trabalham? Pra poder ganhar dinheiro pra comprar coisas que precisam. ( Criança 2, de 10;5 anos, nível II).

- Eu acho que é...é...fazer alguma coisa que as outras pessoas necessitam. - Porque você acha que as pessoas trabalham? Pra ajudar a sociedade. - Você acha que elas recebem alguma coisa pelo trabalho delas? Recebem o salário. - Porque você acha que as pessoas precisam de dinheiro? Pra comprar o que precisam pra viver. (Criança 8, de 11;5 anos, nível II).

Percebe-se, nesta fala, uma noção de relações sociais que se estabelecem entre as pessoas. Além da remuneração, o trabalho é uma forma de produzir algo para o outro.

- O que eu acho que é trabalhar? Trabalhar...é fazer alguma coisa que a gente ganha dinheiro, né? Pra sustentar a família, pra...algumas vezes comprar alguma coisa que precisa, né? Eu acho que é isso. - Porque você acha que as pessoas trabalham? Pra conseguir dinheiro, né? Algumas vezes porque uma pessoa precisa ter uma profissão, né? Precisa trabalhar pra conseguir dinheiro pra ajudar a família quando ela ta precisando, mas o trabalho é muito essencial pras pessoas! (Criança 10, de 11;10 anos, nível II).

- Ah...é quando cê faz alguma coisa e recebe por isso.- Porque você acha que as pessoas trabalham? Pra se sustentar, pra ganhar dinheiro, pra ocupar o tempo...acho que é por isso. - $\mathrm{O}$ que é se sustentar? Sustentar..é...tipo...ganhar o dinheiro por esforço dele, 
pra poder pagar conta, comprar coisas pra família ou mesmo...pra ele mesmo.- Por que você acha que as pessoas precisam de dinheiro? - Porque hoje em dia tudo é dinheiro. (Adolescente 2, de 13;7 anos, nível II).

Nesta fala, aparece outra característica do trabalho, além da finalidade de remuneração: a ocupação do tempo. Outra questão que chama a atenção é o valor que o sujeito já atribui ao dinheiro. As conceituações das crianças a partir de 11 anos apresentam uma articulação mais organizada que a de crianças das faixas etárias anteriores. O trabalho assume importância vital para as pessoas, como demonstram as fala a seguir.

- O que você acha que é trabalhar? - Sei lá (sorri)...um meio de ganhar dinheiro. - Porque você acha que as pessoas trabalham? Pra conseguir dinheiro pra sustentar a família. - O que você acha que é "sustentar a família"? - Arrumar comida pra casa...arrumar é...sei lá...(sorrisos)...televisão...essas coisas básicas, construir uma casa também. (Adolescente 6, de 13;4 anos, nível II).

No nível II, conforme a fala das crianças e adolescentes, o trabalho é um meio para se sustentar, ter mais qualidade de vida e manter não só as necessidades materiais, mas amplia-se sua função para garantias de segurança e manutenção de futuro. As crianças já têm mais informações sobre o funcionamento do mundo, por meio da escolarização e da maior inserção social, o que permite ampliar suas respostas. A média de crianças e adolescentes no nível II, considerando o somatório das subcategorias, foi de 85\% das crianças de 10 anos; 67,5\% das crianças de 6 anos e 55\% dos adolescentes, o que mostra a mobilidade presente neste nível.

O nível III caracteriza-se pelo pensamento formal propriamente dito, constituindo-se na capacidade de pensar sobre aspectos não visíveis da realidade. De acordo com Piaget e Inhelder (1966/1989), a característica mais geral do pensamento formal é a de que ele opera sobre as próprias proposições, ou seja, pelo seu alto grau de descentração e de reversibilidade, 
o pensamento reflete sobre o processo intrínseco do próprio pensar. As respostas são mais elaboradas e mais articuladas que nos níveis anteriores. No Nível III, o sujeito começa a raciocinar não somente sobre o real, mas também sobre o possível e o real passa, assim, a ser somente um componente do possível. O sujeito começa a usar a lógica das proposições para raciocinar sobre o possível o que se caracteriza por basear-se em uma lógica estritamente verbal e numa combinatória. Os extratos a seguir exemplificam as falas das crianças e dos adolescentes do nível III.

- O que você acha que é trabalhar? Trabalhar!? Ah! É...(longo tempo). - Pode falar o que você achar, do jeito que você sabe. É...Depois que cê se forma, ce vai seguir alguma coisa e essa coisa que você seguir, vai trabalhar nela. Ai, nisso ce pode ou trabalhar e ser um funcionário e receber salário ou ser... ser um...tipo...um dentista e receber dos clientes. E nisso vai ganhar uma vida... pra você ter uma casa...comida, ter uma vida boa. - Porque você acha que as pessoas trabalham? - Eu acho que é...pra pessoa sobreviver. O que você acha que é sobreviver? Ah, ter um lugar onde morar, num precisar dormir debaixo da ponte...ter o que comer...é...ter..ter saúde, se precisar ir no médico, se precisar a família pode...pode...levar..tem as...as vantagens ...porque pode ir lá...se precisar de ir no hospital, a família pode levar.. O que as pessoas recebem em troca do trabalho delas? Dinheiro. (Criança 6, de 11;3 anos, nível III).

- Trabalhar? Meio complexa essa pergunta, mas...se...seria cota diária...cê trabalha oito horas, é...normalmente, cinco ou seis dias por semana, a troco de um salário. - Porque você acha que as pessoas trabalham? Pelo dinheiro...pra não ficarem a toa...porque gostam... - Por que você acha que as pessoas precisam de dinheiro? Ah...alimentação...lazer, né? Ah...escola...pros filhos...sei lá! Tudo envolve dinheiro! (Adolescente 10, de 14;2 anos, nível III). 
De acordo com as falas dos adolescentes, percebe-se que eles já apresentam um início de conceituações e apontam outras possibilidades que não se baseiam unicamente em suas percepções da realidade, mas pensam sobre as alternativas a serem buscadas para entrada do indivíduo no mercado de trabalho. A conceituação de trabalho é bem mais elaborada e sistemática do que nas faixas etárias anteriores. Permanece a ideia de "ganhar dinheiro" e este ainda é fundamental como pagamento pelo trabalho, porém ele é consequência do mesmo.

O trabalho é concebido, pelas crianças e adolescentes, como meio para se sustentar, ter mais qualidade de vida e manter não só as necessidades materiais, mas amplia-se sua função para garantias de segurança e manutenção de futuro. O trabalho também começa a ser visto como forma de ocupação do tempo e de realização pessoal, pois pode auxiliar as pessoas a serem felizes. Autores como Delval (2002), Enesco e Purificacion (1995) afirmam que no nível III começa-se a se entender a criação de trabalho por mudanças no sistema social, as influências externas tornam-se visíveis, iniciando-se o entendimento que existem restrições devidas ao sistema social.

\section{B - Compreensão das estratégias de entrada no mercado de trabalho}

Dois tipos de resposta foram encontrados no nível Pré-I: aquelas que não sabem como se consegue um trabalho e as que acreditam que, para conseguir trabalho é preciso somente procurar. Os extratos a seguir exemplificam respostas obtidas na entrevista com as crianças. Encontramos 100\% das crianças de 4 anos, 60\% das crianças de 6 anos e 10\% das crianças de 7 anos no nível Pré-I.

- Como você acha uma pessoa consegue um trabalho? Ela vai pro trabalho. O que ela precisa fazer? Ela procura e vai...(Criança 9, de 4;7 anos, nível Pré-I). 
- Eu acho que a pessoa chama elas e... pra trabalhar, onde ele fica e... ela fica trabalhando lá. (Criança 1, de 6;5 anos, nível Pré-I).

- Não sei! (Criança 10, de 7,7 anos, nível Pré-I).

As crianças afirmam que é só procurar um trabalho e começar a trabalhar. As restrições sociais, a dificuldade de entrar no mercado de trabalho, a necessidade de se qualificar ou de estudar ainda não estão presentes. Este tipo de reposta se deve à ausência de sistemas interpretativos. Os dados da realidade se restringem aos aspectos visíveis, com os quais elas têm contato pois ainda não são capazes de inferências.

No nível I as respostas das crianças compreendem os processos de estudar, pagar pelo trabalho, sair de casa, procurar na rua, como algumas das alternativas para se conseguir um trabalho. Apesar de apresentarem mais possibilidades nas formas de se conseguir um trabalho, a ideia de comprá-lo é mais forte do que nas idades anteriores. O estudo aparece como processo e surge uma hierarquia de ações que vai desde entrar na escola, procurar o trabalho, comprá-lo e mostrar ao empregador o que aprendeu na escola. Ainda não há noção da escassez de trabalho nem das influências externas, confirmando os dados encontrados por Delval (1994, 2002).

O esforço individual é fundamental para obtenção do trabalho. Comprar o trabalho como se compra qualquer mercadoria é uma resposta freqüente no nível I, permanecendo até os 7 anos de idade, não sendo encontradas repostas desse tipo em crianças de 10 anos. Delval (2002) também encontrou este tipo de resposta com crianças até 7 anos.

- Como você acha que uma pessoa consegue um trabalho? Precisa pedir pra outra pessoa... pra prefeitura... precisa... é... é... de dinheiro... - Ela precisa ter dinheiro para conseguir trabalho? (balança a cabeça em sinal positivo). - Por quê? Porque sim. (Criança 1, de 4; 4 anos, nível I). 
- Ela ganha dinheiro e ai procura um trabalho. (Criança 10, de 6;11 anos, nível I).

- Trabalhando. - O que ela precisa fazer para conseguir o trabalho? Pagar. - Pagar o quê? O trabalho. (Criança 9, de 7;6 anos, nível I).

No nível II, conforme Delval (2002), as crianças começam a compreender os processos temporais que constam de várias etapas. Desta forma, as crianças afirmam que há um processo a ser seguido para obtenção de trabalho começando pelo estudo e, em seguida, a procura por trabalho. Caso não se passe por esse processo a pessoa conseguirá um trabalho "ruim" e terá mais dificuldades de entrar no mercado de trabalho. A compreensão desse processo leva as crianças a perceberem as dificuldades de uma pessoa que não estudou para conseguir um trabalho e apontar que, para determinados locais, as exigências de formação são maiores, como é o caso de entrada numa universidade para lecionar. As crianças diferenciam os tipos de trabalhos, apresentando agora "trabalhos bons", que são mais bem pagos, trabalha-se menos e com menor esforço e "trabalhos ruins", que são executados com mais esforço e pelos quais se recebe remuneração menor. Os trabalhos considerados ruins não dependem de estudo e a pessoa cuja formação é baixa deve procurar nos locais em que são oferecidos, como é o caso das empregadas domésticas, pedreiros e trabalhadores de lojas. Estes dados foram também encontrados nas pesquisas de Delval (2002).

As relações sociais se tornam mais amplas, as crianças e os adolescentes, como afirma Delval (2002), começam a estabelecer relações sociais não mais entendidas somente como relações entre os indivíduos, mas entre papéis sociais, como a relação entre comprador e vendedor ou entre chefe e empregado, isto é, relações entre tipos de funções e não entre pessoas. Nos extratos das falas das crianças estas características podem ser vistas. 
- Como uma pessoa consegue um trabalho? Se esforçando? Pra maioria dos empregos hoje em dia, a gente tem que ter estudos, ter diploma...senão....pra conseguir mais fácil. - Se não tiver diploma... Consegue também, mas é mais difícil e aqueles...trabalhos que pagam mal. (Criança 1, de 10;2 anos, nível II).

- Ela precisa estudar, aprender e ter uma universidade, o diploma.

- E se não tiver diploma, não tiver estudado? Olha, o certo é estudar e ter diploma, mas, por exemplo, para trabalhar em loja, às vezes, só precisa ter experiência, saber o serviço... (Criança 4, de 10;11 anos, nível II).

Pode-se perceber que as crianças no nível II acreditam que, além da formação, é necessário esforço para obter trabalho, mas esse esforço, diferente da ideia encontrada no nível anterior, deve estar voltado para um objetivo: trabalhar para ter condições de se sustentar. As possibilidades de conceituação são aumentadas devido às influências sociais, ao desenvolvimento da capacidade de abstração e às estruturas de pensamento que, neste nível, permitem ao adolescente pensar sobre um mundo possível, hipotético, não mais baseado apenas na percepção da realidade.

Para os adolescentes do nível III, além das opções apresentadas no nível II como estudar, querer, se formar etc. há a vontade, compreendida como desejo individual e consiste em tomar consciência das dificuldades que existem para alcançar um estado ou meta e a ação do sujeito deverá ser dirigida à superação dos obstáculos, dos quais ele tem consciência. Este tipo de resposta é também apontado por Delval (2002). Nos extratos a seguir, exemplificamos essas características.

- Como você acha que uma pessoa consegue um trabalho? O que ela precisa fazer? Primeiro, ela precisa estudar. Precisa ter vontade de trabalhar.. e procurar um emprego e ver se aparece. Mas, se não estudar, uma pessoa pode conseguir um trabalho? Consegue... mas não vai ser um emprego tão bom assim... vai 
receber só um salário mínimo, vai ser complicado pra ela sobreviver. - O que seria um"emprego bom"? Emprego bom... é... tipo... ah... eu não sei dizer o que é um emprego bom... é um emprego que dê pra você viver normal, sabe? Não tem que passar dificuldade. O emprego de pedreiro é um emprego que cê não tem que estudar, mas tem que saber as coisas pra construir. (Adolescente 2, de 13;7 anos, nível III).

- Como ela consegue? Normalmente, ela vai atrás. - Como? Ah...assiste o jornal...meu pai quando ele emprega as pessoas, ele coloca anúncios, aí as pessoas interessadas vão atrás. - Além disso, elas precisam fazer mais alguma coisa? Normalmente, o currículo, né. - O que é currículo? É...a...seria uma ficha de experiência...que relata...tipo...o que cê já fez, que graduação você tem...sua capacitação...tudo tá no currículo. - O que é "graduação"? Até onde ce foi na escola. - Quem não estuda, não chega a ter uma graduação, consegue trabalho? Conseguir...consegue, mas não te garanto que seja um trabalho bom. - O que seria um "trabalho bom"? Que ganha bom salário. - Então, se não estudou, ela conseguiria um trabalho... De faxineiro de rua...de gari. - Que ganha menos? Ganha menos. (Adolescente 10, de 14;2 anos, nível III).

Os adolescentes acreditam que há um caminho a ser percorrido para obtenção de trabalho, obedecendo a uma hierarquia dos fatos, ou seja, a pessoa estuda, faz seu currículo, procura emprego e enfrenta a concorrência para obter trabalho. Os estudos não são mais a única forma de se preparar para o trabalho, mas a pessoa que não estudou pode tentar trabalhar no que denominaram de "trabalhos ruins", pelos quais a remuneração é menor, o tempo de trabalho é maior e há dispêndio maior de energia física. Porém, independente de ser um emprego "bom" ou "ruim" deve-se saber executar as tarefas inerentes a cada profissão. A capacidade individual deve ser comprovada para que se entre no mercado de trabalho. Ressaltamos que as 
crianças e adolescentes deste estudo estão inseridos em um contexto social que difere de outros locais. Viçosa é uma cidade universitária e as crianças entram em contato, desde muito cedo, com termos como "universidade", "graduação", "capacitação", "currículo", termos estes já utilizados pelas crianças, como foi mostrado nos extratos apresentados.

Neste estudo, pode-se perceber uma evolução do conceito de trabalho nas representações de crianças e adolescentes, uma vez que os mesmos apresentam respostas denotando níveis diferenciados de compreensão. Isto se deve, segundo Piaget $(1964,1973)$ a um processo contínuo de assimilação e acomodação do sujeito ao mundo social e deste ao sujeito. As transmissões sociais assumem importância impar nesta construção, pois nota-se que as crianças sempre retomam suas experiências pessoais para exemplificar suas respostas. Como pôde ser visto, fica evidente a mobilidade de crianças e adolescentes de uma mesma faixa etária em níveis diferentes de representação.

\section{Conclusão}

A partir da pesquisa com crianças e adolescentes de 4 a 14 anos de idade, obtivemos dados relevantes sobre a construção do conhecimento social, demonstrando que este tipo de conhecimento se dá por níveis, que são coerentes e influenciados pelo meio social em que a criança está inserida, onde a transmissão e as interações sociais são fatores importantes na formação de conceitos pela criança. Percebe-se, em todos os níveis, diferenças individuais, que nos levam a reforçar a ideia de Piaget de que os conhecimentos, mesmo aqueles que a criança adquire por meio das trocas com as pessoas, são transformados pela criança de forma ativa, não se configurando em meras cópias da realidade.

Diante destas considerações, percebe-se a dificuldade que as crianças enfrentam para ultrapassar as ideias concretas e o pensamento ligado ao real para chegar ao pensamento formal. Os fatores apontados por Piaget 
(maturação e hereditariedade; interações e transmissões sociais, exercício e experiência e a equilibração além da afetividade que está presente em cada um desses fatores) explicam porque o desenvolvimento e o meio social influenciam na representação que crianças e adolescentes tem sobre o mundo social e, especificamente, sobre o trabalho. Entretanto, essa assimilação é ativa e sofre transformações, sendo produto original do pensamento da criança.

Nesta pesquisa, os objetivos foram buscar a gênese do conceito de trabalho, identificando e analisando quais são as representações de crianças e adolescentes sobre trabalho. Procuramos ainda examinar as ideias subjacentes às suas representações, de acordo com os níveis de desenvolvimento estudados, levantando-se as tendências gerais presentes em suas respostas. Fundamentamos nossa investigação na teoria piagetiana, cujo pressuposto básico é de que o conhecimento é construído a partir da interação do sujeito com o objeto, evoluindo de um nível mais simples para um nível mais complexo.

A análise dos resultados permitiu confirmar tal hipótese, pois como pôde ser verificado neste estudo, as ideias dos sujeitos sobre o trabalho vão mudando no decorrer de seu processo de desenvolvimento, indo de ideias realistas e ligadas ao real, até uma forma de pensamento em que já é capaz de lançar hipóteses e inferir dados, não mais a partir de uma realidade concreta, mas pensando sobre possibilidades.

Os resultados encontrados neste trabalho sugerem que há uma tendência evolutiva nas representações de crianças e adolescentes sobre a conceituação de trabalho. O trabalho é percebido pelas crianças, mesmo as mais jovens, como algo que as pessoas fazem para sobreviver, por meio do pagamento recebido em troca de suas tarefas laborativas. Como visto, as crianças de 4, 6 e 7 anos não apresentaram conceituações, estando presente em suas respostas o finalismo, característico deste estágio. O dinheiro é a única finalidade do trabalho, entretanto há um inicio da idéia de que as pessoas podem ganhar amigos, conhecimento, etc. No estágio pré-operatório, 
que vai aproximadamente, de dois a seis anos de idade, as crianças possuem pensamento concreto e não conseguem pensar sobre situações abstratas, tomando as ações das pessoas para "dizer" o que é trabalho. Por volta dos seis anos, aparecem as ações que as pessoas fazem como forma de definir o que é trabalho. Chama a atenção a ideia de que o trabalho é "comprador" pelo trabalhador. O trabalho continua sendo um meio para ganhar dinheiro. Permanece ainda o finalismo encontrado em crianças de 4 anos.

Por volta dos sete anos, as crianças iniciam uma transição para o estágio operatório concreto caracterizado pelo pensamento concreto, baseado nas percepções da realidade, mas com modificações importantes no desenvolvimento mental, em que surgem novas formas de organização, atingindo um equilíbrio mais estável. A queda acentuada do egocentrismo permite a coordenação de pontos de vista diferentes. Entretanto, há indícios que a construção do conhecimento social é relativamente mais vagarosa que as transformações cognitivas alcançadas até agora e conforme Delval (2002) as explicações para este fato não estão ainda muito claras. Pode-se considerar que o mundo social é mais complexo que o mundo físico, pois os problemas para este último são facilmente materializáveis por meio de situações com materiais concretos como varetas, pêndulos, sombras e o mesmo não ocorre com os fenômenos sociais.

Aproximadamente, aos 10 anos, as respostas já diferem em grau de complexidade em relação às crianças de 7 anos embora pertençam, teoricamente, ao mesmo estágio de desenvolvimento cognitivo. O uso do termo sustentar, relacionado ao conceito de trabalho, é recorrente e apareceu apenas em uma criança de 7 anos, sendo considerado, portanto, uma novidade no grupo de crianças de 10 anos. Essa constatação nos permite inferir que ha uma tendência diferenciação conceitual dentro do mesmo grupo. Aproximadamente aos 11 anos, as crianças iniciam uma transição para o estágio operatório formal, no entanto, suas conceituações se parecem com as apresentadas pelas crianças de 10 anos. Não encontramos diferenças significativas dentro deste grupo. Há um início de diferenciação 
entre tempo de trabalho e tempo de lazer. As relações passam a ser entendidas como relações sociais e não como relações entre os indivíduos confirmando os resultados encontrados por Sierra e Enesco (1995) e Delval (2002).

No estágio operatório formal, as características do pensamento mudam. Os adolescentes já são capazes de pensar em termos de conceituações, seu pensamento é descentrado e eles possuem a capacidade de pensar de forma abstrata sobre problemas hipotéticos e situações abstratas, formulando suas hipóteses. Os termos sustentar, sobreviver podem ter o mesmo sentido de "ter qualidade de vida". Os estudos aparecem de forma hierárquica na conceituação priorizando-se na escala estudo, formatura, procura pelo trabalho e são esses os passos que devem ser seguidos pelo sujeito. O trabalho é visto como meio para alcançar fins.

Ressaltamos a importância de pesquisas sobre o conhecimento social, uma vez que traduzem o pensamento/representações da criança em seu processo evolutivo e podem se constituir como termômetros para políticas públicas de atendimento à infancia, repercurtindo também em políticas e práticas educacionais. A fala da criança (que tem muito a nos dizer) deve ser valorizada, pois desenvolve-se imersa em uma cultura, trazendo à tona, elementos que muitas vezes, passam despercebidos para os adultos que a educam.

\section{Referências}

ARIÈS, P. História social da criança e da família. 2. ed. Rio de Janeiro: Guanabara, 1986.

CARMO, P. S. A ideologia do trabalho. 15. ed. São Paulo: Moderna, 2005.

CRUZ, S. H. V. A criança fala: a escuta de crianças em pesquisas. São Paulo: Cortez, 2008.

CHAKUR, C. R. S. L. O social e o lógico-matemático na mente infantil: cognição, valores e representações ideológicas. São Paulo: Arte e Ciência. 2002. 
DELVAL, R. Algumas reflexiones sobre los derechos de los niños. Infância y sociedad, Madrid, n. 27/28, p. 14-41, 1994.

Introdução à prática do método clínico: descobrindo o pensamento das crianças. Porto Alegre: Artmed, 2002.

ENESCO, I.; NAVARRO, I. La comprensión de la organización social en niños y adolescentes. Madrid: CIDE. 1995.

LA TAILLE, I . Desenvolvimento do juízo moral e afetividade na teoria de Jean Piaget. In: Piaget, Vygotsky e Wallon: teorias psicogenéticas em discussão. São Paulo: Summus, 1992.

LEI n. 8.069, de 13 de julho de 1990. "Dispõe sobre o Estatuto da Criança e do Adolescente e dá outras providências". Diário Oficial da União, Brasília: DF, 16 de julho de 1990 .

MARCONI, M. A.; LAKATOS, E. M. Técnicas de pesquisa. 4. ed. São Paulo: Atlas, 1999.

MIGEOTTE, L. Os filósofos gregos e o trabalho na antiguidade. In: MERCURE, D.; SPURK, J. (orgs). O trabalho na história do pensamento ocidental. Petrópolis: Vozes, 2005.

MORIN, E. Os sentidos do trabalho. In: WOOD, T. (Ed.). Gestão empresarial: o fator humano. São Paulo: Atlas, 2002. p. 13-34.

TONELLI, M. J.; PLIOPAS, A. O trabalho e seus sentidos. Psicologia e Sociedade, Belo Horizonte, n. 19 (Especial), p. 47-56, 2007.

PIAGET, J. A Epistemologia Genética. Petrópolis: Vozes, 1971. (ed. orig. 1970).

Estudos sociológicos. Rio de Janeiro: Forense, 1973.

. Da lógica da criança à lógica do adolescente. São Paulo: Pioneira, 1976.

Biologia e conhecimento. 2. ed. Petrópolis: Vozes, 1996. (ed. orig. 1967).

A linguagem e o pensamento da criança. 7. ed. São Paulo: Martins Fontes, 1999. (ed. orig. 1966).

. A representação do mundo na criança. São Paulo: Idéias e letras, 2005. (ed. orig. 1926).

. Seis estudos de psicologia. 24. ed. Rio de Janeiro: Forense Universitária, 2007. (ed. orig. 1964).

INHELDER, B. A psicologia da criança. 2. ed. Rio de Janeiro: Difel, 2006. (ed. orig. 1968). 
SALAMITO, J. M. Trabalho e trabalhadores na obra de Santo Agostinho. In: MERCURE, D.; SPURK, J. (orgs). O trabalho na história do pensamento ocidental. Taborda. Petrópolis: Vozes, 2005.

SALLES, L. M. F. Infância e adolescência na sociedade contemporânea: alguns apontamentos. Estudos de psicologia, Campinas, v. 22, n. 1., jan./mar., 2005.

RAMALHO, J. R; SANTANA, M. A. Sociologia do trabalho no mundo contemporâneo. Rio de Janeiro: Jorge Zahar, 2004.

WADSWORTH, B. Piaget para o professor da pré-escola e o $1^{\circ}$ grau. São Paulo: Pioneira, 1987.

Recebido em 04 de dezembro de 2017. Aprovado em 05 de fevereiro de 2018. 